\title{
Synthesis of Block Copolymers by Transformation of Free Radical Promoted Cationic Polymerization to Atom Transfer Radical Polymerization
}

\author{
Mustafa Degirmenci ${ }^{\dagger}$ and Aysegul TopraK \\ Harran University, Science Faculty, Department of Chemistry, Sanliurfa 63300, Turkey
}

(Received April 7, 2005; Accepted May 27, 2005; Published September 15, 2005)

\begin{abstract}
The transformations of free radical promoted cationic polymerization to atom transfer radical polymerization (ATRP) to form the block copolymers of cyclohexene oxide (CHO) with styrene (St) were performed. In the first step, bromine terminated poly $(\mathrm{CHO}) \mathrm{s}(\mathrm{PCHO}-\mathrm{Br})$ were prepared by free radical promoted cationic polymerization of $\mathrm{CHO}$ monomer in the presence of 2-oxo-1,2-diphenylethyl-2-bromopropanoate, shortly bromo benzoin, (B-Br) and an onium salt namely 1-ethoxy-2-methylpyridinium hexafluorophosphate $\left(\mathrm{EMP}^{+} \mathrm{SbF}_{6}{ }^{-}\right)$as the initiating system. The bromine functionalized polymers thus prepared were used as initiators in ATRP of St, in bulk, in conjunction with $\mathrm{CuBr} / 2,2^{\prime}$-bipyridine as catalyst gave well-defined block copolymer of $\mathrm{CHO}$ and St. Block copolymer formations were evidenced by ${ }^{1} \mathrm{H}$ NMR and gel permeation chromatography (GPC) measurements. [DOI 10.1295/polymj.37.700]

KEY WORDS Block Copolymer / Free Radical Promoted Cationic Polymerization / Atom Transfer Radical Polymerization / Transformation Reactions /
\end{abstract}

In recent years, there have been various methods proposed and used for the synthesis of block copolymers. Among them the transformation polymerization is an alternative method that allows combining various polymerization mechanisms. By using this way many monomers with different chemical structure can be polymerized to yield block copolymers with novel properties. In this approach monomer 1 is polymerized by a mechanism "A" to produce a polymer with a functional group $\mathrm{F}$ which is capable of initiating polymerization by a different mode/mechanism "B" as shown in Scheme 1.

Many examples concerning the use of transformation polymerization reactions for preparing block copolymers were reported and reviewed by many authors. ${ }^{1-10}$

$\mathrm{N}$-alkoxy pyridinium salts are effective initiators for the cationic polymerization of cyclic ethers such as cyclohexene oxide and vinyl ethers such as $n$-butyl vinyl ether. ${ }^{11}$ Their photoactivity can be tuned to a broad wavelength range by the use of free radical sources, ${ }^{12}$ charge transfer complexes ${ }^{13}$ and photosensitizers. ${ }^{14}$

Photosensitized cationic polymerization has attracted particular interest since the triggering of the initiation may be extended to much longer wavelengths, where pyridinium salts are transparent and photosensitizers such as benzoin and its derivatives, benzophenon, and acylphosphin oxides absorb the light. It was shown that the oxidation of electron donor radicals to corresponding carbocations may conveniently be used to promote cationic polymerization of com- pounds such as epoxides, cyclic ethers, and alkyl vinyl ethers. The overall process may be presented by the following reaction (Scheme 2).

This so-called free radical promoted cationic polymerization is an elegant and fairly flexible way to extend the spectral response of onium salts to 300$400 \mathrm{~nm}$ regions.

A variety of controlled/living radical polymerization (CRP) techniques, such as stable free radical polymerization (SFRP), reversible addition-fragmentation chain transfer (RAFT), and atom transfer radical polymerization (ATRP), have been developed in recent years. ${ }^{15-27}$ Among them, ATRP, developed by Matyjaszewski and co-workers, is one of the most efficient methods to control radical polymerization and has been studied extensively because of the broad range of monomers and the mild polymerization conditions. $^{28}$

This study focuses on the new approach for preparation of PCHO-PSt block copolymers by the transformation of promoted cationic polymerization to ATRP. Thus bromine terminated PCHO synthesized by the free radical promoted cationic polymerization was used as a macroinitiator for the ATRP of styrene to give the well-defined block copolymers. To the best of our knowledge, however, there has been no report on preparing of bromine end-functional polyCHO and use it a prepolymer for ATRP.

${ }^{\dagger}$ To whom correspondence should be addressed (Fax: +90 414 3440051, E-mail: mustafa@ harran.edu.tr). 


$$
\begin{aligned}
& \mathrm{I}+\mathrm{nM}_{1} \stackrel{\text { mechanism A }}{\longrightarrow} \mathrm{I}-\mathrm{M}_{1} \neg_{\mathrm{n}-1} \mathrm{M}_{1} * \stackrel{\text { Termination }}{\longrightarrow} \mathrm{I}-\mathrm{M}_{1} \neg_{\mathrm{n}} \mathbf{F} \\
& \left.\left.\left.\mathrm{I}-\mathrm{M}_{1}\right]_{\mathrm{n}} \mathbf{F}+\mathrm{mM}_{2} \stackrel{\text { mechanism B }}{\longrightarrow} \mathrm{I}-\mathrm{M}_{1}\right\rceil_{\mathrm{n}} \text { block } \leftarrow-\mathrm{M}_{2}\right]_{\mathrm{m}}
\end{aligned}
$$

Scheme 1 .

\section{EXPERIMENTAL}

\section{Materials}

Cyclohexene oxide (CHO) (Aldrich) and styrene (St) (Fluka) and solvents were purified by conventional drying and distillation procedures. 2-Oxo-1,2diphenylethyl-2-bromopropanoate (B-Br) was prepared as described previously. ${ }^{29,30}$ 1-Ethoxy-2-methylpyridinium hexafluorophosphate $\left(\mathrm{EMP}^{+} \mathrm{SbF}_{6}{ }^{-}\right)$ was prepared according to a procedure described by Reichard. ${ }^{31}$ Diphenyliodonium hexafluorophosphate (Fluka), CuBr (Aldrich), 2,2'-bipyridine (Merck) were used as received.

\section{Free Radical Promoted Cationic Polymerization}

Prior to irradiation in a merry-go-round type photoreactor equipped with 16 Philips $8 \mathrm{~W} / 08$ lamps emitting light nominally at $350 \mathrm{~nm}$ at room temperature, argon was bubbled through the solutions of $\mathrm{CHO}$ in bulk containing $\mathrm{B}-\mathrm{Br}$ and onium salt. At the end of irradiation the solutions were poured into cold methanol. In order to prevent direct absorption by the onium salt, a phenantrene solution $\left(1 \times 10^{-2} \mathrm{~mol} \cdot \mathrm{L}^{-1}\right)$ was used as filter throughout the work. The precipitated bromine terminated poly(cyclohexene oxide) (PCHO$\mathrm{Br}$ ) was filtered off and dried in vacuo.

\section{Preparation of Block Copolymers by Atom Transfer Radical Polymerization}

A schlenk tube equipped with magnetic stirrer was used. The system was vacuumed and back-filled with argon several times. Catalyst $(\mathrm{CuBr})$, ligand bipyridine (bpy), initiator (PCHO-Br), and monomer (St) were introduced under inert atmosphere. The tube was placed in an oil bath warmed at $110^{\circ} \mathrm{C}$ and stirred at that temperature. After a given time, the mixture was diluted with $\mathrm{CH}_{2} \mathrm{Cl}_{2}$ and poured into ten-fold methanol. The solid was collected after filtration and drying at $40^{\circ} \mathrm{C}$ in vacuum overnight. In order to remove the complex salts from the block polymers they were re-dissolved in THF and passed through an alumina column followed by precipitation in methanol.

\section{Characterizations}

${ }^{1} \mathrm{H}$ NMR spectra were recorded on a Bruker

$$
\mathrm{R} \cdot+\mathrm{On}^{+} \stackrel{\mathrm{h} v}{\longrightarrow} \mathrm{R}^{+}+\mathrm{On} \cdot
$$

\section{Scheme 2.}

$250 \mathrm{MHz}$ spectrometer with $\mathrm{CDCl}_{3}$ as the solvent and tetramethylsilane as the internal standard. IR spectra were recorded on a Perkin-Elmer spectrum RXI FT-IR spectrophotometer. UV-vis spectra were recorded on a Shimadzu 1601 spectrophotometer. Gel permeation chromatography (GPC) analyses were performed with a set up consisting of an Agilent 1100 RI apparatus equipped with three Waters ultrastyragel columns (HR series 4, 3, 2 narrow bore), with THF as the eluent at a flow rate of $0.3 \mathrm{~mL} / \mathrm{min}$ and a refractive index detector. Molecular weights of Polymers were calculated by using of polystyrene standards.

\section{RESULTS AND DISCUSSION}

Figure 1 shows UV absorption spectra of $\mathrm{B}-\mathrm{Br}$ and $\mathrm{EMP}^{+} \mathrm{SbF}_{6}{ }^{-}$. As can be seen from this figure, pyridinium salt does not absorb at $350 \mathrm{~nm}$, the light is absorbed only by B-Br.

Free radical promoted cationic polymerization of $\mathrm{CHO}$ was performed by using bromo benzoin (B-Br) and onium salts. The photochemically generated bromo benzyl radicals reduce the pyridinium salt to yield corresponding carbocations capable of initiating cat-

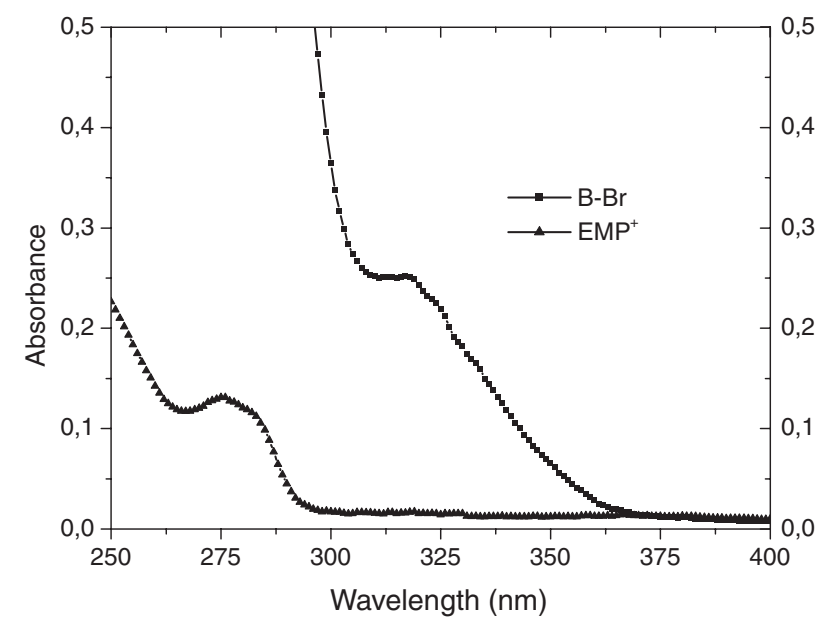

Figure 1. $\mathrm{UV}$ absorption spectra of $\mathrm{B}-\mathrm{Br}$ and $\mathrm{EMP}^{+} \mathrm{PF}_{6}{ }^{-}$at $5 \times 10^{-4} \mathrm{~mol} / \mathrm{L}$ in $\mathrm{CH}_{2} \mathrm{Cl}_{2}$. 


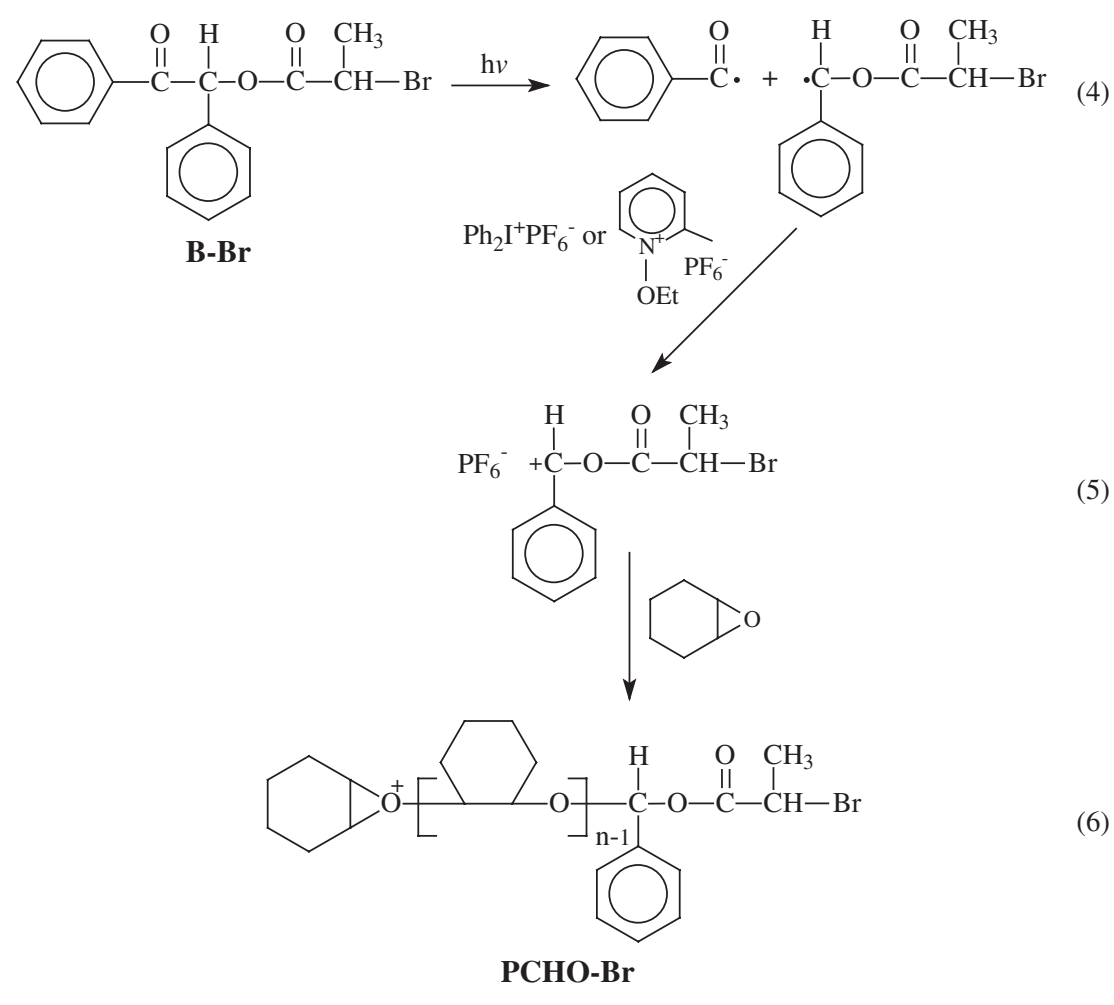

Scheme 3.

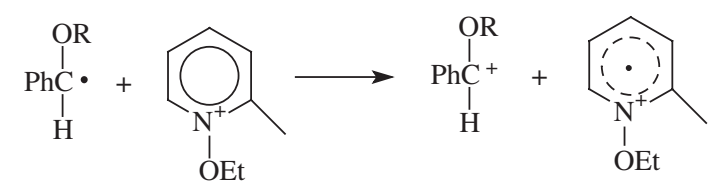

Scheme 4.

ionic polymerization of $\mathrm{CHO}$ as shown in Scheme 3. The benzoyl radicals formed concomitantly can not initiate the polymerization of cationic polymerizable monomers such as $\mathrm{CHO}$. The influence of factors, such as light intensity, onium salt concentration or the type of radical source onto the rate of radical induced cationic polymerization with benzoin derivative/ onium salt systems has been carefully investigated. ${ }^{32}$

As can be seen from Table I, CHO was polymerized quite effectively by using $\mathrm{EMP}^{+}$as an oxidizing agent. It is assumed that in the system under consideration the alkoxyalkyl radical, which was formed upon irradiation according to Scheme 4, acts as a fairly powerful reducing agent. ${ }^{33}$

The pyridinyl radical formed in this way is very short lived. ${ }^{12}$ Its decomposition according to following reaction occurs very rapidly.

On this basis, $\mathrm{EMP}^{+}$was expected to be quite appropriate for the generation of carbocations via reaction with electron-donating radicals, because the occurrence of back reaction in this process can be excluded.

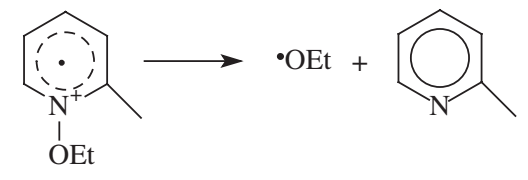

\section{Scheme 5.}

In the case of iodonium salt higher polymer yields are obtained and it is appeared to be the most efficient onium salt. This behavior may be attributed to the tail absorption of the iodonium salt. Under these conditions direct initiation by the iodonium salt to same extent can not be prevented. A different situation was encountered in the case of the triphenylsulfonium salt. This salt is not capable of initiating the free radical promoted cationic polymerization; this can be explained in terms of the quite different redox potentials (relative to SEC) of the three salts: $-1.2 \mathrm{~V}\left(\mathrm{Ph}_{3} \mathrm{~S}^{+}\right),{ }^{34}$ $-0.2 \mathrm{~V}\left(\mathrm{Ph}_{2} \mathrm{I}^{+}\right),{ }^{35}$ and $-0.7 \mathrm{~V}\left(\mathrm{EMP}^{+}\right){ }^{12}$

Bromine-terminated poly(cyclohexene oxide) was characterized in detail by IR and ${ }^{1} \mathrm{H}$ NMR spectral measurement. The IR spectrum of $\mathrm{PCHO}-\mathrm{Br}$ contains 


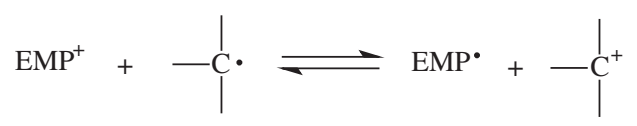

Scheme 6.

Table I. Synthesis of bromine-terminated PCHO by free radical promoted cationic polymerization at room temperature in bulk

\begin{tabular}{cccccccc}
\hline Run & $\begin{array}{c}\text { Initiator }(\mathrm{B}-\mathrm{Br}) \\
(\mathrm{mmol} / \mathrm{L})\end{array}$ & $\begin{array}{c}\mathrm{EMP}^{+} \\
(\mathrm{mmol} / \mathrm{L})\end{array}$ & $\begin{array}{c}\mathrm{Ph}_{2} \mathrm{I}^{+} \\
(\mathrm{mmol} / \mathrm{L})\end{array}$ & $\begin{array}{c}\text { Irradiation Time } \\
(\mathrm{min})\end{array}$ & $\begin{array}{c}\text { Conversion } \\
(\%)\end{array}$ & $M_{\mathrm{n}}{ }^{\mathrm{a}}$ & $M_{\mathrm{w}} / M_{\mathrm{n}}$ \\
\hline 1 & 5 & 5 & - & 30 & 22 & 6550 & 1.17 \\
2 & 10 & 10 & - & 15 & 46 & 5100 & 2.23 \\
3 & 5 & - & 5 & 20 & 49 & 7750 & 2.18 \\
4 & 10 & - & 10 & 15 & 87 & 3500 & 2.16 \\
$5^{\mathrm{b}}$ & 5 & - & - & 60 & 0 & - & - \\
\hline
\end{tabular}

$[\mathrm{CHO}]_{\mathrm{o}}=9.91 \mathrm{~mol} / \mathrm{L}$ (in bulk), $\lambda_{\text {inc }}=350 \mathrm{~nm},{ }^{\mathrm{a}}$ Determined by GPC according PSt standards, ${ }^{\mathrm{b}} \mathrm{Ph}_{3} \mathrm{~S}^{+}$was used as onium salt.

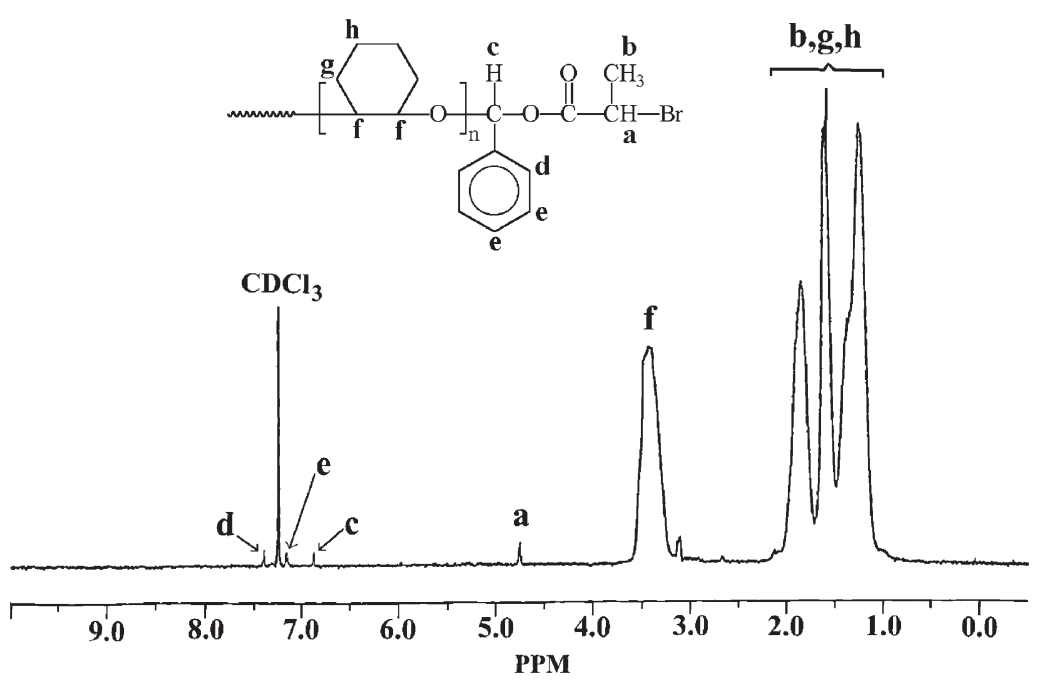

Figure 2. ${ }^{1} \mathrm{H}$ NMR spectra of PCHO-Br (Table I, Run 2) in $\mathrm{CDCl}_{3}$.

characteristic $\mathrm{CO}$ ester band and ether group of $\mathrm{PCHO}$ at 1733 and $1086 \mathrm{~cm}^{-1}$, respectively. The ${ }^{1} \mathrm{H}$ NMR spectra recorded in $\mathrm{CDCl}_{3}$ in Figure 2 evidenced resonance signals of protons of relative intensities corresponding to the number and type of protons. The complete functionalization of $\mathrm{PCHO}$ is expected because of the explained reasons and purification of block copolymer given following.

The ATRP of St was carried out by using PCHO-Br as macroinitiator and $\mathrm{CuBr} / 2,2^{\prime}$-bipyridine as catalyst in bulk at $110^{\circ} \mathrm{C}$. Table II shows experimental conditions and characterization data of the block copolymers of cyclohexene oxide with styrene generated from ATRP. The conversions were determined gravimetrically. In order to know whether there is unfunctionalized PCHO or not, the block copolymers was boiled in $n$-hexane, since $n$-hexane is a solvent for PCHO. In all cases, homopolymer (PCHO) formation was found about $1-2 \%$. We assume that the precipitat- ed homo PCHO comes from unfunctionalized PCHO and fucntionaliztion of PCHO is completed. The composition of the copolymers was estimated from ${ }^{1} \mathrm{H}$ NMR data by using the ratio of the peak intensities at $3.41 \mathrm{ppm}$ (f protons of PCHO segment in Figure 2) to that appearing at $6.56-7.06 \mathrm{ppm}$ (aromatic protons of PSt segment) (Figure 4).

The measured and calculated $M_{\mathrm{n}}$ values are in good agreement indicating that well-defined block copolymers were obtained. For example in Table II Run 7, $15 \%$ conversion was reached after $3 \mathrm{~h}$ and the copolymer with $M_{\mathrm{n}, \mathrm{GPC}}=13200$ and polydispersity of 1.33 was obtained. The theoretical molecular weight $\left(M_{\mathrm{n}, \mathrm{th}}=12500\right)$ and molecular weight calculated from ${ }^{1} \mathrm{H}$ NMR spectrum $\left(M_{\mathrm{n}, \mathrm{HNMR}}=13700\right)$ are close to that obtained from GPC measurements.

The theoretical molecular weights $\left(M_{\mathrm{n}, \mathrm{th}}\right)$ were calculated by using the following equation with the assumption that all of the $\mathrm{PCHO}-\mathrm{Br}$ molecules initiate 


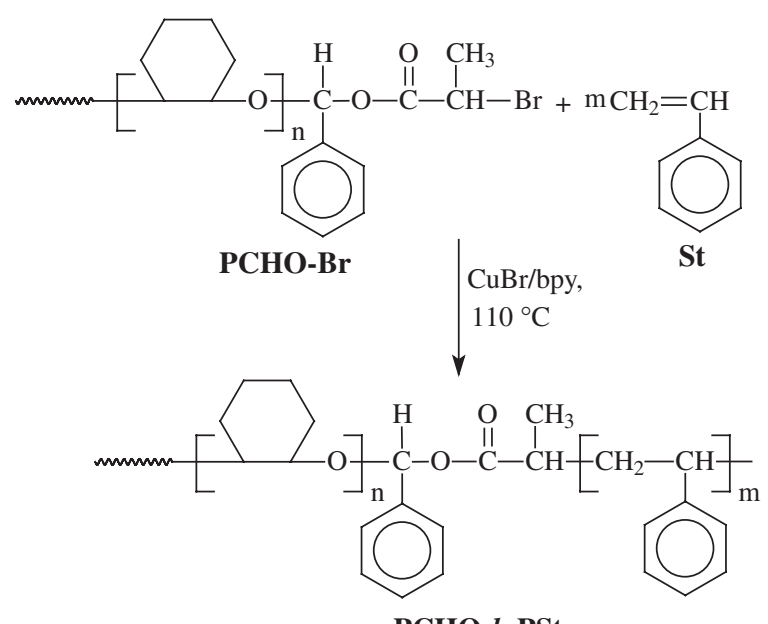

(10)

PCHO- $b$-PSt

Scheme 7.

Table II. Block copolymerization of styrene ${ }^{\text {a }}$ by ATRP initiated by bromine-terminated $\mathrm{PCHO}^{\mathrm{b}}$ in the presence of $\mathrm{CuCl}_{2} / \mathrm{bpy}^{\mathrm{c}}$ at $110^{\circ} \mathrm{C}$

\begin{tabular}{ccccrcc}
\hline Run & $\begin{array}{c}\text { Time } \\
(\mathrm{h})\end{array}$ & $\begin{array}{c}\text { Conversion } \\
(\%)\end{array}$ & $M_{\text {ntheo. }}$ & $M_{\mathrm{nGPC}}$ & $M_{\mathrm{w}} / M_{\mathrm{n}}$ & $M_{\text {nH-NMR }}$ \\
\hline 6 & 2 & 11 & 10200 & 9800 & 1.21 & 10100 \\
7 & 3 & 15 & 12500 & 13200 & 1.33 & 13700 \\
8 & 5 & 22 & 15300 & 15700 & 1.35 & 16100 \\
9 & 7 & 30 & 19000 & 20200 & 1.28 & 22000 \\
\hline
\end{tabular}

${ }^{\mathrm{a}}[\mathrm{St}]=8.73 \mathrm{~mol} / \mathrm{L}$ (in bulk), ${ }^{\mathrm{b}} M_{\mathrm{n}}=5100$, and $100 \mathrm{~g} / \mathrm{L}$ (Table I, Run 2), ${ }^{\mathrm{c}}$ Init./[CuCl 2$] /[\mathrm{bpy}]($ mol ratio $=1 / 1 / 3)$.

the polymerization and no termination by coupling occurred:

$$
\bar{M}_{\mathrm{n}, \mathrm{th}}=\frac{\left[\bar{M}_{\mathrm{o}}\right]}{\left[\mathrm{I}_{\mathrm{o}}\right]} \times\left(M_{\mathrm{w}, \mathrm{St}}\right) \times(\text { Conversion })+\bar{M}_{\mathrm{n}, \mathrm{PCHO}-\mathrm{Br}}
$$

where $M_{0}$ and $\mathrm{I}_{0}$ are the initial molar concentrations of monomer, St and initiator, $\mathrm{PCHO}-\mathrm{Br}$, respectively, and $M_{\mathrm{w}, \mathrm{St}}$ and $M_{\mathrm{n}, \mathrm{PCHO}-\mathrm{Br}}$ are the molecular weight of the monomer and prepolymer, respectively.

Figure 3 illustrated the GPC curves of the precursor brominated poly(cyclohexene oxide), and the PCHOPSt block copolymer, respectively. The peak at a higher molecular weight is ascribed to the block copolymer. The molecular weight distributions of the products after ATRP reactions were relatively narrow $\left(M_{\mathrm{w}} / M_{\mathrm{n}} \sim 1.3\right)$. The GPC profiles shifted toward higher molecular weight and no signal shoulder attributed to the starting brominated poly(cyclohexene oxide) was detected. These indicated that pure block copolymers of poly(cyclohexene oxide)/styrene were synthesized with $\mathrm{PCHO}-\mathrm{Br}$ in conjunction with $\mathrm{CuBr}$ and bpy. The efficient blocking is ascribed to the high initiating reactivity of bromine terminated poly(cyclohexene oxide).

The molecular weight distributions after ATRP

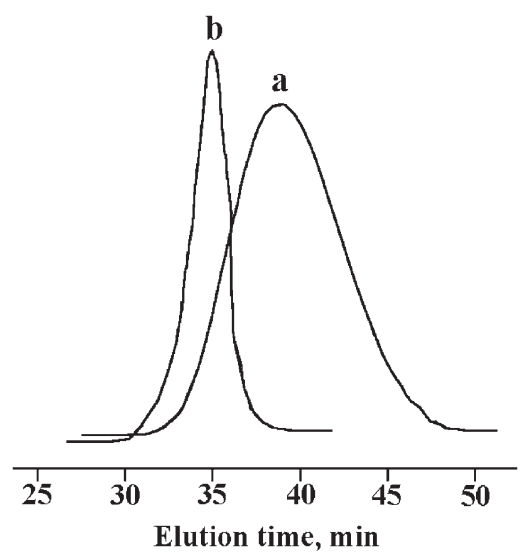

Figure 3. GPC traces of PCHO-Br (Table I, Run 2) (a) and PCHO-PSt block copolymer (Table II, Run 7) (b).

reactions are lower than those starting polymer (PCHO-Br) and GPC traces of block copolymers are very narrow in comparison with $\mathrm{PCHO}-\mathrm{Br}$. This is due to the well-control polymerization techniques (ATRP) applied.

The structures of the copolymers were then analyzed by ${ }^{1} \mathrm{H}$ NMR spectroscopy. Figure 4 shows ${ }^{1} \mathrm{H}$ NMR spectrum of the block copolymer of cyclohexene oxide with styrene (Table II, Run 6). In addition to the absorption of $-\mathrm{O}-\mathrm{CH}-\mathrm{CH}-\mathrm{O}-$ protons $(\mathbf{k})$ from the brominated poly $(\mathrm{CHO})$ at $3,41 \mathrm{ppm}$, there appeared the absorptions of the phenyl group of styrene repeat units at $6.56-7.06 \mathrm{ppm} .{ }^{1} \mathrm{H}$ NMR results further demonstrated the formation of the well-defined block copolymer of cyclohexene oxide and styrene.

The GPC results, along with the ${ }^{1} \mathrm{H}$ NMR spectral analysis, suggested that the ATRP blocking of styrene initiated with brominated poly(cyclohexene oxide) was in living fashion and gave the desired poly(cyclohexene oxide)-block-polystyrene.

In conclusion, we report the method for the synthe- 


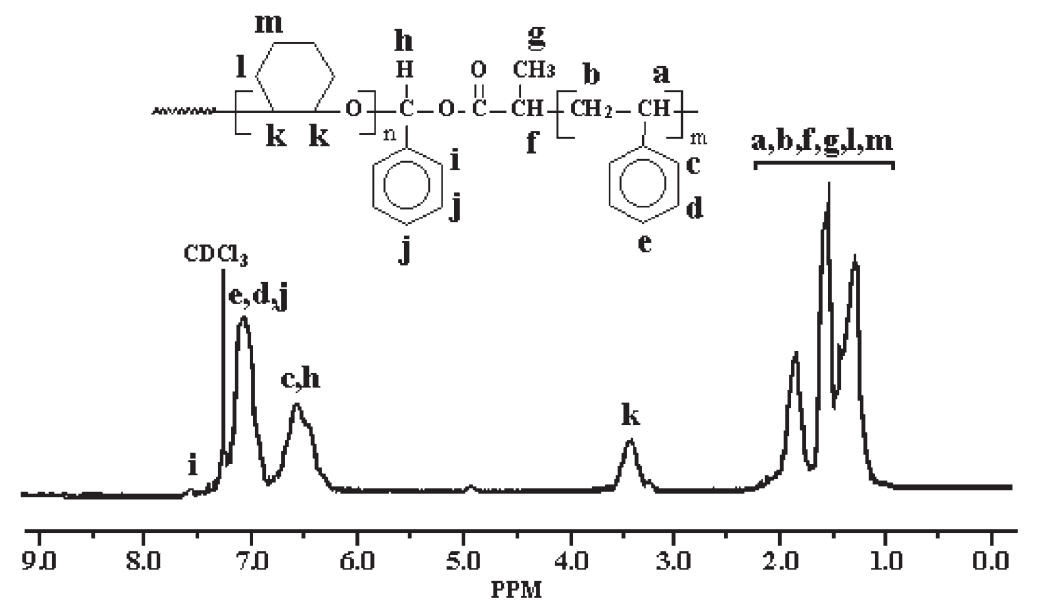

Figure 4. ${ }^{1} \mathrm{H}$ NMR spectra of PCHO-PSt block copolymer (Table I, Run 6) in $\mathrm{CDCl}_{3}$.

sis of block copolymers of cyclohexene oxide with styrene by the transformation of free radical promoted cationic polymerization to ATRP. Cyclohexene oxide polymer carrying bromine-end functional (PCHO-Br) was prepared by free radical promoted cationic polymerization method using $\mathrm{B}-\mathrm{Br}$ and onium salts. The obtained PCHO-Br can be used as an efficient macroinitiator in the ATRP of styrene in the presence of $\mathrm{CuBr}$ and bpy to give block copolymer of cyclohexene oxide and styrene with predetermined molecular weight and narrow molecular weight distribution.

Acknowledgment. We gratefully acknowledge financial support by Scientific Research Council (HÜBAK) of Harran University.

\section{REFERENCES}

1. F. Schue, in "Comprehensive Polymer Science," Vol. 6, S. G. Allen and J. C. Bevington, Ed., Pergamon, Oxford, U.K., 1989, chapt. 10, p 664.

2. Y. Yagci and M. K. Mishra, in "Macromolecular Design: Concept and Practice: Macromonomers, Macroinitiators, Macroiniferters, Macroinimers, Macroiniters, and Macroinifers," M. K. Mishra, Ed., Polymer Frontiers International, Inc., New York, N.Y., 1994, chapt. 10, p 391.

3. Y. Yagci, in "Advanced Functional Molecules and Polymers," Vol. 1, H. S. Nalwa, Ed., Gordon \& Breach Science Publishers, Amsterdam, 2001, chapt. 4, p 233.

4. Y. Yagci and M. K. Mishra, in "Polymeric Materials Encyclopedia," J. C. Salamone, Ed., CRC Press, Boca Raton, FL., 1996, p 789.

5. K. Matyjaszewski, Ed. "Controlled Radical Polymerization," ACS Symposium Series, American Chemical Society, Washington DC, 1998, vol. 685.

6. J. Lu, H. Liang, A. Li, and Q. Cheng, Eur. Polym. J., 40, 397 (2004)

7. M. A. Tasdelen, M. Degirmenci, Y. Yagci, and O. Nuyken, Polym. Bull., 50, 131 (2003).

8. I. Erel, I. Cianga, E. Serhatli, and Y. Yagci, Eur. Polym. J.,
38, 1409 (2002).

9. A. B. Düz and Y. Yagci, Eur. Polym. J., 35, 2031 (1999).

10. H.-Q. Guo, A. Kajiwara, Y. Morishima, and M. Kamachi, Macromolecules, 29, 2354 (1996).

11. Y. Yagci and W. Schnabel, Macromol. Symp., 85, 115 (1994).

12. A. Böttcher, K. Hasebe, G. Hizal, P. Stelberg, Y. Yagci, and W. Schnabel, Polymer, 32, 2289 (1991).

13. G. Hizal, Y. Yagci, and W. Schnabel, Polymer, 35, 2428 (1994).

14. Y. Yagci, I. Lukac, and W. Schnabel, Polymer, 34, 1130 (1993).

15. B. Keoshkerian, M. K. Georges, and D. Boils-Boissier, Macromolecules, 28, 6381 (1995).

16. T. Fukuda, T. Terauchi, A. Goto, Y. Tsujii, and T. Miyamoto, Macromolecules, 29, 3050 (1996).

17. D. Benoit, S. Grimaldi, S. Robin, J. P. Finet, P. Tordo, and Y. Gnanou, J. Am. Chem. Soc., 122, 5929 (2000).

18. Y. K. Chong, T. P. T. Le, G. Moad, E. Rizzardo, and S. H. Thang, Macromolecules, 32, 2071 (1999).

19. R. T. A. Mayadunne, E. Rizzardo, J. Chiefari, G. Moda, A. Postma, and S. H. Thang, Macromolecules, 33, 243 (2000).

20. A. Goto, K. Sato, Y. Tsujii, T. Fukuda, G. Moad, E. Rizzado, and S. H. Thang, Macromolecules, 34, 402 (2001).

21. T. E. Patten, J. Xia, T. Abernathy, and K. Matyjaszewski, Science, 272, 866 (1996).

22. J. S. Wang and K. Matyjaszewski, Macromolecules, 28, 7901 (1995).

23. S. G. Gaynor, S. Edelman, and K. Matyjaszewski, Macromolecules, 29, 1079 (1996).

24. C. J. Hawker, J. Am. Chem. Soc., 116, 11185 (1994).

25. M. Kato, M. Kamigaito, M. Sawamoto, and T. Higashimura, Macromolecules, 28, 1721 (1995).

26. V. Percec and B. Barboiu, Macromolecules, 28, 7970 (1995).

27. M. Kamigaito, T. Ando, and M. Sawamoto, Chem. Rev., 101, 3689 (2001).

28. K. Matyjaszewski and J. H. Xia, Chem. Rev., 101, 2921 (2001).

29. M. Degirmenci, I. Cianga, G. Hizal, and Y. Yagci, Polym. Prepr. Am. Chem. Soc., Div. Polym. Chem., 43, 22 (2002).

30. Y. Yagci and M. Degirmenci, in "Advances in Controlled/ 
Living Radical Polymerization,” Vol. 854, K. Matyjaszewski, Ed., ACS Symposium Series, American Chemical Society, Washington, DC, 2003, chapt. 27, p 383.

31. C. Reichardt, Chem. Ber., 99, 1769 (1966).

32. Y. Yagci and A. Ledwith, J. Polym. Sci., Polym. Chem. Ed., 26, 1911 (1988).
33. Y. Yagci, A. Onen, and W. Schnabel, Macromolecules, 24, 4620 (1991).

34. P. S. McKinney and S. Rosenthal, J. Electroanal. Chem. Soc., 16, 261 (1968).

35. H. E. Bachofner, F. M. Beringer, and L. Meites, J. Am. Chem. Soc., 80, 4269 (1958). 